Opinion

\title{
Vitamin D in Patients with Chronic Hepatitis C Virus Infection Receiving the Direct Antiviral Agents
}

Hsuan-Wei Chen, Hsuan-Hwai Lin, Yu-Lueng Shih, Tsai-Yuan Hsieh, Jung-Chun Lin *

Division of Gastroenterology, Department of Internal Medicine, Tri-Service General Hospital, National Defense Medical Center, Taipei, Taiwan; E-Mails: meindongsha@gmail.com, redstone120@yahoo.com.tw, albreb@ms28.hinet.net,tyh1216@ms46 .hinet.net, doc10506@gmail.com

* Correspondence: Jung-Chun Lin; E-Mail: doc10506@yahoo.com

Academic Editor: Chung-Feng Huang

Special Issue: Unmet Need in the Management of Chronic Hepatitis C

OBM Hepatology and Gastroenterology

2020, volume 4, issue 1

doi:10.21926/obm.hg.2001044

\section{Keywords}

Vitamin D; chronic hepatitis C; liver disease
Received: February 23, 2020

Accepted: March 23, 2020

Published: March 30, 2020

Recent studies have investigated the relationship between the vitamin $D$ status of patients with chronic hepatitis $\mathrm{C}(\mathrm{CHC})$ [1]. Some researchers found no insufficient vitamin $D$ in noncirrhotic viral liver disease [2]. However, the majority insisted that the hepatitis C virus (HCV)-positive subjects have deficient vitamin D levels [3-5]. Similarly, in our CHC cohort [6], up to $38 \%$ of the HCV infected patients had vitamin D deficiency $(<20 \mathrm{ng} / \mathrm{mL})$.

Some in vitro studies have uncovered the synergic effect of vitamin $D$ and interferon-based treatment in inhibiting HCV RNA replication [7-9]. Consistent with these findings, some researchers reported a positive correlation between 25-hydroxyvitamin $D_{3}$ levels and the success rate of achieving the sustained virological response (SVR) [10-12], but others failed to establish any

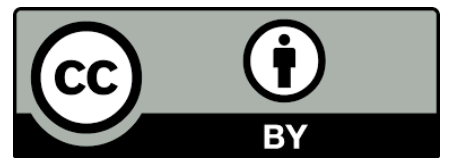

(C) 2020 by the author. This is an open access article distributed under the conditions of the Creative Commons by Attribution License, which permits unrestricted use, distribution, and reproduction in any medium or format, provided the original work is correctly cited. 
consistency in results [13-16]. However, in the era of direct antiviral agents (DAA), pre-treatment vitamin $D$ level does not impact treatment response $[17,18]$.

It has been known that $1,25(\mathrm{OH})_{2} \mathrm{D}_{3}$ treatment could be able to slow the fibrotic progression of hepatic stellate cells, via the transduction of vitamin D-vitamin-D-receptor signaling. This signaling pathway inhibits the expression of pro-fibrogenic genes and reduces liver fibrosis induced by thioacetamide in vitro and in vivo, respectively [18]. These findings suggest a role of vitamin $D$ deficiency in liver fibrosis. However, patients' clinical data remain scarce and inconclusive.

Another issue is concerning the kinetic changes in vitamin D after achieving SVR, but even in this case, the data are inadequate. Only Lange et al. investigated serum vitamin $D$ status before and after antiviral therapy in $50 \mathrm{HCV}$ patients with SVR. They discovered a trend toward a lower incidence of severe vitamin D deficiency after HCV eradication. An improved hepatic function resulted from the eradication of HCV may also positively contribute to the production of vitamin D. However, it should also be clarified that whether hypovitaminosis $D$ regresses or worsens after SVR.

In summary, despite vitamin D deficiency is common in $\mathrm{CHC}$, vitamin D level has no synergic effect with DAA therapy in HCV-infected patients. However, among patients who achieved an SVR for HCV, some patients (48\%) did not regress after SVR, and some (6\%) even worsened, with an increased risk for hepatocellular carcinoma [19]. Therefore, further clinical studies are required to evaluate the role of vitamin $D$ in hepatic fibrogenesis and possible therapeutic use of supplementation of vitamin D in patients after the SVR.

\section{Acknowledgments}

We thank the patients who participated in this study. This study was supported in part by the grants from the Foundation for Medical Research of Tri-Service General Hospital (TSGH-C99-167 \& TSGH-C-108-074).

\section{Author Contributions}

HW.C. and JC.L. drafted the article. HW.C., HH.L., YL.S., TY.H., and JC.L. recruited the patients, analyzed and interpreted the data. TY.H. gave a critical advice. JC.L. edited the article and approved the final version to be published. All authors read and approved the final manuscript.

\section{Competing Interests}

There is no conflict of interest to disclose.

\section{References}

1. Kitson MT, Roberts SK. D-livering the message: The importance of vitamin D status in chronic liver disease. J Hepatol. 2012; 57: 897-909.

2. Duarte MP, Farias ML, Coelho HS, Mendonça LM, Stabnov LM, do Carmo d Oliveira M, et al. Calcium-parathyroid hormone-vitamin D axis and metabolic bone disease in chronic viral liver disease. J Gastroenterol Hepatol. 2001; 16: 1022-1027.

3. Bitetto D, Fattovich G, Fabris C, Ceriani E, Falleti E, Fornasiere E, et al. Complementary role of vitamin $\mathrm{D}$ deficiency and the interleukin-28B rs12979860 C/T polymorphism in predicting 
antiviral response in chronic hepatitis C. Hepatology. 2011; 53: 1118-1126.

4. Lange CM, Bojunga J, Ramos-Lopez E, von Wagner M, Hassler A, Vermehren J, et al. Vitamin D deficiency and a CYP27B1-1260 promoter polymorphism are associated with chronic hepatitis $C$ and poor response to interferon-alfa based therapy. J Hepatol. 2011; 54: 887-893.

5. Petta S, Cammà C, Scazzone C, Tripodo C, Di Marco V, Bono A, et al. Low vitamin D serum level is related to severe fibrosis and low responsiveness to interferon-based therapy in genotype 1 chronic hepatitis C. Hepatology. 2010; 51: 1158-1167.

6. Lin JC, Hsieh TY, Wu CC, Chen PJ, Chueh TH, Chang WK, et al. Association between chronic hepatitis $C$ virus infection and bone mineral density. Calcif Tissue Int. 2012; 91: 423-429.

7. Huang JF, Ko YM, Huang CF, Yeh ML, Dai CY, Hsieh MH, et al. 25-Hydroxy vitamin D suppresses hepatitis $C$ virus replication and contributes to rapid virological response of treatment efficacy. Hepatol Res. 2017; 47: 1383-1389.

8. Gal-Tanamy M, Bachmetov L, Ravid A, Koren R, Erman A, Tur-Kaspa R, et al. Vitamin D: An innate antiviral agent suppressing hepatitis $C$ virus in human hepatocytes. Hepatology. 2011; 54: 1570-1579.

9. Matsumura $T$, Kato $T$, Sugiyama N, Tasaka-Fujita $M$, Murayama $A$, Masaki $T$, et al. 25-hydroxyvitamin D3 suppresses hepatitis C virus production. Hepatology. 2012; 56: 1231-1239.

10. Bitetto D, Fattovich G, Fabris C, Ceriani E, Falleti E, Fornasiere E, et al. Complementary role of vitamin $D$ deficiency and the interleukin-28B rs12979860 C/T polymorphism in predicting antiviral response in chronic hepatitis C. Hepatology. 2011; 53: 1118-1126.

11. Petta S, Camma C, Scazzone C, Tripodo C, Di Marco V, Bono A, et al. Low vitamin D serum level is related to severe fibrosis and low responsiveness to interferon-based therapy in genotype 1 chronic hepatitis C. Hepatology. 2010; 51: 1158-1167.

12. Lange CM, Bojunga J, Ramos-Lopez E, von Wagner M, Hassler A, Vermehren J, et al. Vitamin D deficiency and a CYP27B1-1260 promoter polymorphism are associated with chronic hepatitis $C$ and poor response to interferon-alfa based therapy. J Hepatology. 2011; 54: 887-893.

13. Belle A, Gizard E, Conroy G, Lopez A, Bouvier-Alias M, Rouanet S, et al. 25-OH vitamin D level has no impact on the efficacy of antiviral therapy in naïve genotype $1 \mathrm{HCV}$-infected patients. United European Gastroenterol J. 2017; 5: 69-75.

14. Kitson MT, Dore GJ, George J, Button P, McCaughan GW, Crawford DH, et al. Vitamin D status does not predict sustained virologic response or fibrosis stage in chronic hepatitis $C$ genotype 1 infection. J Hepatology. 2013; 58: 467-472.

15. Kitson MT, Sarrazin C, Toniutto P, Eslick GD, Roberts SK. Vitamin D level and sustained virologic response to interferon-based antiviral therapy in chronic hepatitis C: A systematic review and meta-analysis. J Hepatology. 2014; 61: 1247-1252.

16. Loftfield E, O'Brien TR, Pfeiffer RM, Howell CD, Horst R, Prokunina-Olsson L, et al. Vitamin D Status and Virologic Response to HCV Therapy in the HALT-C and VIRAHEP-C Trials. PloS One. 2016; 11: e0166036.

17. Backstedt D, Pedersen M, Choi M, Seetharam A. 25-Vitamin D levels in chronic hepatitis C infection: Association with cirrhosis and sustained virologic response. Ann Gastroenterol. 2017; 30: 344-348.

18. Gayam V, Mandal AK, Khalid M, Mukhtar O, Gill A, Garlapati P, et al. Association between Vitamin $\mathrm{D}$ levels and treatment response to direct-acting antivirals in chronic hepatitis C: A 
real-world study. Gastroenterology Res. 2018; 11: 309-316.

19. Tachi Y, Hirai T, Miyata A, Ohara K, lida T, Ishizu Y, et al. Progressive fibrosis significantly correlates with hepatocellular carcinoma in patients with a sustained virological response. Hepatol Res. 2015; 45: 238-246.

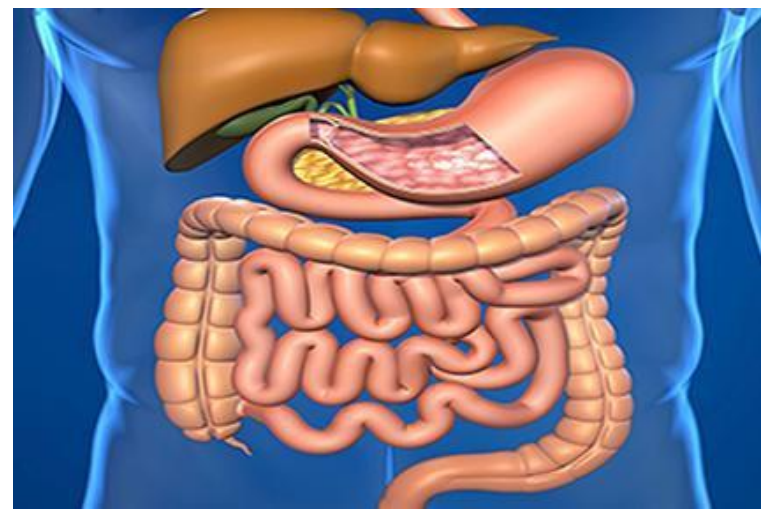

Enjoy OBM Hepatology and Gastroenterology by:

1. Submitting a manuscript

2. Joining in volunteer reviewer bank

3. Joining Editorial Board

4. Guest editing a special issue

For more details, please visit:

http://www.lidsen.com/journals/hg 